\title{
Validación del protocolo de Producción de Semilla de Papa usando Ambientes Controlados (Sistema CETS), en especies cultivadas de papa (Solanum tuberosum L.)
}

\author{
A.H. del Rio ${ }^{1 / *}$, C. Obregon ${ }^{2}$, J.B. Bamberg ${ }^{3}$, J. Petrick$^{4}$, R. Bula ${ }^{4}$, F. de la Calle ${ }^{4}$
}

Recibido: $10 / 04 / 2017$

Aceptado: 06/11/2017

Acceso en línea: Diciembre 2017

\section{Resumen}

Bajos niveles productivos de papa en el Perú y otros países de la región son atribuidos al poco uso de semilla de calidad y reciclaje de tubérculos contaminados. Por ello hay consenso en la necesidad de incorporar tecnologías de producción de semilla de calidad que sean efectivas y eficientes pero que sean consecuentes con la realidad de la papa en Latinoamérica. Este estudio examinó un sistema tecnológico de producción de semillas desarrollado por la compañía americana CETS de Wisconsin. Este sistema usa cámaras de crecimiento llamadas fitotrones donde los parámetros de crecimiento son todos controlados automáticamente. Las plantas pueden producir mini-tubérculos entre 60 y 70 días, permitiendo hasta seis cosechas por año. Para validar el uso de esta tecnología diez variedades nativas de ocho especies cultivadas de papa fueron usadas. Los resultados demostraron que las plantas completaron sus ciclos fenológicos y fisiológicos dentro de los rangos de tiempos establecidos. La producción de tubérculos fue variable, en algunos casos fue muy alta (Solanum $x$ ajanhuiri) pero en otros fue solo moderada (S. phureja). En resumen, el sistema de CETS ofrece una posibilidad para la producción de semilla de calidad en variedades de papas nativas de la región. Este sistema podría también tener impacto en otras áreas como conservación de biodiversidad, mejoramiento genético e investigación básica.

Palabras clave adicionales: Diversidad genética, papas nativas, semilla de papa, fitotron.

\section{Validation of high-quality potato seed production protocol under controlled conditions (CETS System) in cultivated potato species (Solanum tuberosum L.)}

\section{Summary}

Low potato yield in Peru and other countries in the region are attributed to the use of low quality seeds and tuber recycling. Therefore, there is consensus on the need of incorporating seed production technologies that are effective and efficient but also consistent with the reality of potato in Latin America. This examined a technology for high-quality potato seed production developed by CETS, a US company based in Wisconsin. This system uses growth chambers called phytotrons where growing conditions are all automatically controlled. The plants would thus produce mini-tubers between 60 and 70 days, allowing up to 6 harvests per

\footnotetext{
Autor para correspondencia: correo electrónico: adelrioc@wisc.edu University of Wisconsin Department of Horticulture, US Potato Genebank.

ADERS-PERU, Prolong. Arenales 343, San Isidro, Lima Peru.

USDA/Agricultural Research Service, 4312 Hwy 42, Sturgeon Bay, WI, 54235, USA.

CETS LLC, 386 County Road M Grand Marsh WI 53936.
} 
year. To validate the use of CETS system, 10 native varieties of the eight Andean cultivated potato species were used as models. The results showed that the plants were capable of completing phenological and physiological phases under phytotron conditions within the expected timeframe. Levels of production of mini-tubers were variable, in some cases yield was high (Solanum $x$ ajanhuiri) but in others it was moderate as in $S$. phureja. In summary, CETS technology is a possibility for the production of high-quality tuber seed in varieties of native potatoes in the region. This system unlocks chances of a positive impact on other areas such as biodiversity conservation, potato breeding and basic research.

Additional key words: Genetic diversity, native potatoes, potato seed, Phytotron,

\section{Introducción}

La producción sostenible de papa en niveles competitivos depende de la generación y uso de semilla de alta calidad. El uso de tubérculos libres de enfermedades permite alcanzar el máximo de potencial productivo (Frost et al. 2013). En países con niveles masivos de producción comercial, el uso y flujo constante de semillas de papa de alta calidad es imperativo (Guenthner et al. 1991). Por otro lado reciclaje de tubérculos de la cosecha es contraproducente ya que lleva consigo alto riesgo de usar semillas contaminadas y la transmisión de pestes y enfermedades (Solomon-Blackburn y Barker 2001).

Arenas-Calle et al. (2015) enfatizó que América Latina necesita promover condiciones necesarias para el crecimiento del sector semillero mediante fortalecimientos en la capacitación y en la investigación. En el Perú la semilla de calidad es poco usada, tanto dentro de agricultores comerciales como entre los pequeños productores. La utilización de semilla certificada en el Perú ha sido tradicionalmente menor del 1\% (Ezeta 2001). La producción de semilla de calidad podría también contribuir con los esfuerzos de conservación y protección de estas formas nativas (Graddy 2013).

Entre los métodos tradicionales de producción de semillas están cultivo de meristemos y producción de minitubérculos usando hidroponía y aeroponia (Chiipanthenga et al. 2012, MateusRodriguez et al. 2013). Todos ellos han sido implementados en diversos países con mucho éxito. Una metodología adicional es el uso de ambientes controlados desarrollado por la compañía norteamericana CETS (por sus siglas en inglés para Sistema de Producción de Semilla de Papa usando Ambientes Controlados) (Houlihan 2013, Houlihan 2014). El fundamento es la producción de semillas dentro de cámaras de crecimiento llamadas fitotrones donde sistemas computarizados regulan parámetros ambientales y nutritivos con precisión y consistencia. Una de sus mayores ventajas es que puede ser implementado en cualquier zona climática ya que las condiciones externas no influyen en su funcionamiento. Este sistema acelera el desarrollo fisiológico de las plantas pudiendo completar desarrollo y producción de tubérculos en periodos de 60 a 70 días, abriendo la posibilidad de completar hasta seis ciclos de producción por año (Houlihan 2013, Houlihan 2014). Esta tecnología bajo patente de CETS es regularmente usada en variedades Americanas de la especie cultivada Solanum tuberosum. Sin embargo en Latinoamérica, las variedades nativas se originan de otras ocho especies diferentes las cuales nunca han sido propagadas usando este sistema. Este trabajo tuvo como objetivo validar el sistema CETS en variedades nativas de las especies cultivadas de papa. Esto podría ofrecer una alternativa adicional de producción de semilla en la región. 


\section{Materiales y métodos}

\section{Material Vegetal.}

Se utilizaron 10 variedades de papas nativas de origen geográfico diverso. Estas variedades corresponden a las ocho especies de papa cultivada de Latinoamérica que de acuerdo a los tratados taxonómicos de Hawkes (1990) y,
Huaman y Spooner (2002). La Tabla 1 presenta la lista de estos materiales que tienen orígenes en Bolivia, Colombia, Ecuador y Perú. Todas estas accesiones fueron donadas por el Banco de Germoplasma de Papa de los Estados Unidos (USPG) https://www.arsgrin.gov/nr6/.

Tabla 1. Lista de variedades de papa nativa usada en el estudio.

\begin{tabular}{|c|c|c|c|}
\hline Codigo $^{1}$ & Donante/Especie ${ }^{2}$ & $\begin{array}{l}\begin{array}{l}\text { Nombre de la } \\
\text { Nativa }\end{array} \\
\text { Variedad } \\
\end{array}$ & Origen \\
\hline 604207 & PROINPA - S. x curtilobum & Chiar Choque Pitu & Bolivia \\
\hline 631419 & CIP 701830 - S. goniocalyx & Garhuash Huayro & Peru \\
\hline 599280 & CIP $702802-$ S. $x$ ajanhuiri & Jancko Ajawiri & Bolivia \\
\hline 607472 & PROINPA - S. stenotomum & Khuchi Akita & Bolivia \\
\hline 664477 & CIP 705332 - S. andigena & Leona & Ecuador \\
\hline 599259 & PROINPA - S. x juzepczukii & Lucky & Bolivia \\
\hline 607498 & CIP 704217 - S. x chaucha & Runtu Huayro & Peru \\
\hline 611072 & CIP 700223 - S. andigena & Yana Imilla & Peru \\
\hline 665407 & CIP 704218 - S. phureja & Yema de Huevo & Colombia \\
\hline 642181 & CIP 701591 - S. andigena & Yuracc Ccompis & Peru \\
\hline
\end{tabular}

${ }^{1}$ Codigo, representa el número de accesión usado por el Banco de Germoplasma de EEUU para identificar esta entrada; ${ }^{2}$ Donante: PROINPA, Fundación para la Promoción e Investigación de Productos Andinos de Bolivia; CIP, Centro Internacional de la Papa. El número adicional representa el código de identificación de la entidad donante.

\section{Cámaras de crecimiento controlado (Fitotrones)}

Este estudio fue llevado a cabo en las instalaciones de la compañía CETS en Grand Marsh, Wisconsin, EEUU. Los fitotrones son cámaras de crecimiento con condiciones ambientales controladas usando un sistema computarizado. Los mini-tubérculos producidos en fitotrones son llamados AstroTubers ${ }^{\mathrm{TM}}$ por CETS para diferenciarlos de los minitubers producidos por cultivo de tejidos, hidroponía o aeroponia. Detalles adicionales de este sistema CETS pueden ser encontrados en http://www.cetstech.com/

\section{Producción de plantas en fitotrones}

Cien plántulas in vitro, diez para cada una de las variedades listadas en la Tabla 1 fueron usadas para el primer paso de producción de plantas madres. El proceso incluye el sembrado de estas en bandejas de plástico de $25.4 \mathrm{~cm}$. x $35.6 \mathrm{~cm}$. x 5.0 $\mathrm{cm}$. con un sustrato de siembra que es una combinación de 1:1 vermiculita y hojuelas de madera de coco. Las bandejas fueron luego colocadas dentro de los fitotrones para el desarrollo de las plantas. Los parámetros fueron riego con la solución comercial nutritiva de CETS (Grand Marsh, Wisconsin), esta es una modificación de solución nutritiva de 
Hoagland. La aplicación fue cada 2 horas por 4 segundos durante el día mientras en la noche cada $3 \mathrm{~h} / 2 \mathrm{~s}$ por las primeras dos semanas, luego $5 \mathrm{~h} / 2 \mathrm{~s}$. Después de 4 o 5 semanas, las plantas madres alcanzan una altura que oscila entre 18 y $25 \mathrm{~cm}$ que es el momento para ser usadas en la colección de esquejes. Los esquejes son sembrados en nuevas bandejas para generar plantas de producción. En este trabajo se sembraron entre 40 y 60 esquejes por cada bandeja conteniendo el mismo sustrato de 1:1 vermiculita y hojuelas de coco. La Tabla 2, indica los parámetros usados.

Tabla 2. Parámetros de crecimiento de plantas de papas nativas en condiciones controladas del sistema CETS

\begin{tabular}{lllllllll}
\hline & $\begin{array}{l}\text { Número } \\
\text { de } \\
\text { horas } \\
\text { de día }\end{array}$ & $\begin{array}{l}\text { Temperatura } \\
\text { de día }\left({ }^{\circ} \mathrm{C}\right)\end{array}$ & $\begin{array}{l}\text { Némero } \\
\text { horas } \\
\text { de } \\
\text { noche }\end{array}$ & $\begin{array}{l}\text { Temperatura } \\
\text { de noche }\left({ }^{\circ} \mathrm{C}\right)\end{array}$ & $\begin{array}{l}\text { Intensidad } \\
\text { de luz }\end{array}$ & $\begin{array}{l}\text { Tiempo } \\
\text { de riego } \\
\text { en } \\
\text { dia }{ }^{1}\end{array}$ & $\begin{array}{l}\text { Tiempo } \\
\text { de riego } \\
\text { en } \\
\text { noche }\end{array}$ & $\begin{array}{l}\text { pH } \\
\text { nutrientes }\end{array}$ \\
\hline 1 & 12 & 25 & 12 & 20 & Mínima & $2 \mathrm{~h} / 4 \mathrm{~s}$ & $3 \mathrm{~h} / 2 \mathrm{~s}$ & 5.5 \\
2 & 11 & 20 & 13 & 15 & Media & $3 \mathrm{~h} / 4 \mathrm{~s}$ & $3 \mathrm{~h} / 2 \mathrm{~s}$ & 5.5 \\
3 & 11 & 20 & 13 & 15 & Máxima & $4 \mathrm{~h} / 2 \mathrm{~s}$ & $4 \mathrm{~h} / 2 \mathrm{~s}$ & 5.0 \\
4 & 11 & 20 & 13 & 10 & Máxima & $5 \mathrm{~h} / 4 \mathrm{~s}$ & $5 \mathrm{~h} / 2 \mathrm{~s}$ & 5.0 \\
5 & 11 & 18 & 13 & 10 & Máxima & $5 \mathrm{~h} / 4 \mathrm{~s}$ & $5 \mathrm{~h} / 2 \mathrm{~s}$ & 5.5 \\
6 & 11 & 18 & 13 & 10 & Máxima & $6 \mathrm{~h} / 4 \mathrm{~s}$ & $8 \mathrm{~h} / 2 \mathrm{~s}$ & 5.5 \\
7 & 11 & 18 & 13 & 10 & Máxima & $6 \mathrm{~h} / 4 \mathrm{~s}$ & $8 \mathrm{~h} / 2 \mathrm{~s}$ & 5.7 \\
8 & 12 & 20 & 12 & 10 & Máxima & $6 \mathrm{~h} / 2 \mathrm{~s}$ & $8 \mathrm{~h} / 2 \mathrm{~s}$ & 5.7 \\
10 & 12 & 25 & 12 & 15 & Máxima & $6 \mathrm{~h} / 4 \mathrm{~s}$ & 0 & 5.7 \\
\hline
\end{tabular}

${ }^{1}$ La frecuencia de riego en horas (h). Tiempo de aplicación en segundos (s).

\section{Resultados}

\section{Crecimiento de plantas de papas nativas en fitotrones}

Las papas nativas mostraron un desarrollo similar a lo esperado en los estándares de crecimiento en este sistema para las variedades americanas. Las condiciones de crecimiento de las plantas madres fueron la temperatura constante de $20^{\circ} \mathrm{C}$ con 13 horas de luz/11 horas de oscuridad por los primeros 14 días. Luego los siguientes 14 días la misma temperatura de $20^{\circ} \mathrm{C}$ pero el fotoperiodo fue cambiado a $11 \mathrm{~h} \mathrm{luz} / 13 \mathrm{~h}$ oscuridad.
Desarrollo de plantas y producción de tubérculos en Solanum $x$ curtilobum (2n $=5 x=60$ )

Las plantas de la variedad Chiar Choquepitu alcanzaron entre 12 a $15 \mathrm{~cm}$, con crecimiento erecto y combinación de tallos gruesos o semi-gruesos (entre 12-14 y 9-11 mm de diámetro, respectivamente) con hojas medianas a pequeñas. Los minitubérculos fueron redondeados de color purpura brillante con un promedio de 94 mini-tubérculos por bandeja (área aproximada de la bandeja es $0.088 \mathrm{~m}^{2}$ ) (Tabla 3). 
Tabla 3. Producción de tubérculos para cada variedad de papa nativa usada en este estudio

\begin{tabular}{|c|c|c|c|c|c|}
\hline $\begin{array}{l}\text { Código } \\
\text { de USPG }\end{array}$ & Especie & Nombre de Variedad & $\begin{array}{l}\text { Numero de } \\
\text { Plántulas } \\
\text { in vitro } \\
\text { usadas }\end{array}$ & $\begin{array}{l}\text { Promedio de } \\
\text { tubérculos por } \\
\text { bandeja } \\
\text { En } \pm 2 \text { meses }\end{array}$ & $\begin{array}{l}\text { Promedio por } \\
\text { Fitotron (14 } \\
\text { Bandejas) } \\
\text { En } \pm 2 \text { meses }\end{array}$ \\
\hline 604207 & Solanum $\times$ curtilobum & Chiar Choque Pitu & 10 & 94 & 1,316 \\
\hline 631419 & Solanum goniocalyx & Garhuash Huayro & 10 & 108 & 1,512 \\
\hline 599280 & Solanum $x$ ajanhuiri & Jancko Ajawiri & 10 & 238 & 3,325 \\
\hline 607472 & Solanum stenotomum & Khuchi Akita & 10 & 75 & 1,050 \\
\hline 664477 & $\begin{array}{l}\text { Solanum tuberosum L. subsp. } \\
\text { Andigena }\end{array}$ & Leona & 10 & 15 & 210 \\
\hline 599259 & Solanum x juzepczukii & Lucky & 10 & 60 & 840 \\
\hline 607498 & Solanum $x$ chaucha & Runtu Huayro & 10 & 83 & 1,155 \\
\hline 611072 & $\begin{array}{l}\text { Solanum tuberosum L. subsp. } \\
\text { Andigena }\end{array}$ & Yana Imilla & 10 & 205 & 2,870 \\
\hline 665407 & Solanum phureja & Yema de Huevo & 10 & 15 & 210 \\
\hline \multirow[t]{2}{*}{642181} & $\begin{array}{l}\text { Solanum tuberosum L. subsp. } \\
\text { andigena }\end{array}$ & Yuracc Ccompis & 10 & 75 & 1,050 \\
\hline & & & 100 & 97 & 1,354 \\
\hline
\end{tabular}

Solanum goniocalyx $(2 n=2 x=24)$

Las plantas de Garhuash Huayro fueron muy altas entre 25 a $30 \mathrm{~cm}$. con abundante follaje. El crecimiento fue erecto y la mayoría de los tallos semi-gruesos en grosor (9 a $11 \mathrm{~mm}$ de diámetro). Los minitubérculos fueron redondos de color amarillo ligero. En promedio se colectaron 108 tubérculos por bandeja (Tabla 3).

\section{Solanum $x$ ajanhuiri $(2 n=2 x=24)$}

Jancko Ajawiri tuvo vigor notable con plantas de 20 a $25 \mathrm{~cm}$ de altura con combinaciones de tallos delgados y semigruesos (alrededor de 6-8 y 9-11 mm de diámetro, respectivamente) y follaje abundante. Los mini-tubérculos fueron de color blanco-amarillento brillante de forma alargada. Esta tuvo la mejor producción con un promedio de 238 tubérculos por bandeja (Tabla 3).

Solanum stenotomum $(2 n=2 x=24)$
La variedad Khuchi Akita mostro hojas elongadas pero de grosor relativamente delgado. Las plantas fueron pequeñas oscilando entre 10 a $12 \mathrm{~cm}$., de color verde brillante. Los tallos delgados $(6-7 \mathrm{~mm})$ combinaban el color verde con el purpura en algunas zonas, lo mismo ocurría en las nervaduras de las hojas. Mini-tubérculos fueron de color purpura/morado oscuro y de forma alargada y curvados. El número estimado fue de 1050 mini-tubérculos por fitotron (Tabla 3).

Solanum tuberosum. subsp. andigena ( $2 n$ $=4 x=48$ )

Plantas de la variedad Leona tuvieron crecimiento vigoroso. El tamaño fue entre 18 a $20 \mathrm{~cm}$ con tallos semi-gruesos (9-11 $\mathrm{mm}$ ). Las hojas fueron ovaladas de tamaño mediano. Número de tubérculos fue bajo, solo 15 mini-tubérculos por bandeja o 210 por fitotron (Tabla 3). La variedad Yana Imilla tuvo crecimiento vigoroso, sin embargo sus plantas fueron pequeñas, 
alrededor de $10 \mathrm{~cm}$ y crecimiento erecto. Las hojas fueron ovaladas y alargadas relativamente pequeñas, en algunos casos las hojas tenían una ligera coloración purpura en las nervaduras. Tubérculos fueron ovalados, de color morado. En promedio 2870 mini-tubérculos por fitotron (Tabla 3). Yuracc Ccompis tuvo plantas de crecimiento erecto o semierecto, con tallos de grosor mediano (8-10 $\mathrm{mm}$ de diametro). Las hojas y los tallos con coloración purpura, sobretodo en el envés de las hojas. Los mini-tubérculos fueron de tamaño irregular, generalmente redondos de color amarillento. $\mathrm{La}$ producción fue de alrededor de 75 minitubérculos por bandeja (Tabla 3).

\section{Solanum $x$ juzepczukii $(2 n=3 x=36)$}

La variedad Boliviana Lucky mostró tallos delgados y plantas pequeñas, oscilando entre 8 y $10 \mathrm{~cm}$. Las hojas contrastaban con el tamaño pequeño de las plantas ya que estas eran grandes, gruesas de forma ovalada-redonda con algunas ondulaciones. Los mini-tubérculos de color crema brillante ligeramente redondos. El número de mini-tubérculos tuvo un estimado de 840 por fitotron (Tabla 3).

Solanum $x$ chaucha $(2 n=3 x=36)$

Runtu Huayro reveló plantas con crecimiento erecto y tallos vigorosos. Las hojas fueron medianas a pequeñas. El tamaño de las plantas fue entre 10 y $12 \mathrm{~cm}$. Los mini-tubérculos fueron de color rojo intenso con formas redondas mayormente pero también con algunos ligeramente ovalados. La producción fue de 83 minitubérculos por bandeja (Tabla 3 ).

Solanum phureja $(2 n=2 x=24)$

La variedad Yema de Huevo tuvo plantas vigorosas con hojas gruesas, grandes y robustas de forma ovalada. Los tallos también fueron gruesos; sin embargo el tamaño de las plantas fue más bien pequeño (alrededor de $8-10 \mathrm{~cm}$ ). Los minitubérculos fueron de color ligeramente naranja, de forma redonda. La producción fue baja, solo 15 por bandeja para un total de 210 mini-tubérculos por fitotron (Tabla $3)$.

\section{Discusión}

La producción de semilla de papa de alta calidad es un componente crítico y fundamental en varios aspectos de la cadena productiva. Basados en la realidad del Perú, es evidente que existe mucho interés en explorar sistemas de generación de semilla que sean efectivos y eficientes pero también fáciles de implementar y mantener. Desde esas perspectivas el sistema usado aquí parece cumplir con esos requisitos y adiciona la posibilidad de rápida producción.

Los resultados confirman que es posible ser usados en variedades nativas. Comparativamente estas respondieron dentro los estándares de desarrollo fenológico y fisiológico de variedades Americanas usadas regularmente para producción comercial (Houlihan 2013, Houlihan 2014).

En todos los casos las variedades nativas tuvieron establecimiento efectivo. Cada variedad mostró diferencias morfológicas, inherentes a las características de la especie, ello fue reflejado en variaciones en tamaño de planta, follaje, grosor de tallos, coloraciones y morfología foliar, entre otros. Los mini-tubérculos también presentaron variaciones en color y formas, en muchos casos exhibieron un brillo de piel atractivo que es inusual de ver en tubérculos cosechados en campo. La Figura 1 muestra algunos ejemplos de plantas y tubérculos producidos en fitotrones. Las variedades Jancko Ajawiri $(S . x$ ajanhuiri) y Yana Imilla ( $S$. andigena) mostraron producción notable de tubérculos (Tabla 3). Si asumimos que es posible seis cosechas en un año, esta variedad de $S . x$ ajanhuiri podría producir cerca de 20.000 semillas anualmente en un fitotron de 2.5 metros cuadrados. Sin embargo el otro extremo fue observado en 
Yema de Huevo (S. phureja) y Leona (S. tuberosum subsp. andigenum). Tal vez el origen geográfico de estas requiere otros estudios para hacer ajustes en fotoperiodo y temperatura.

Figura 1. Algunos ejemplos de las plantas y tubérculos producidos en este estudio usando el sistema CETS.

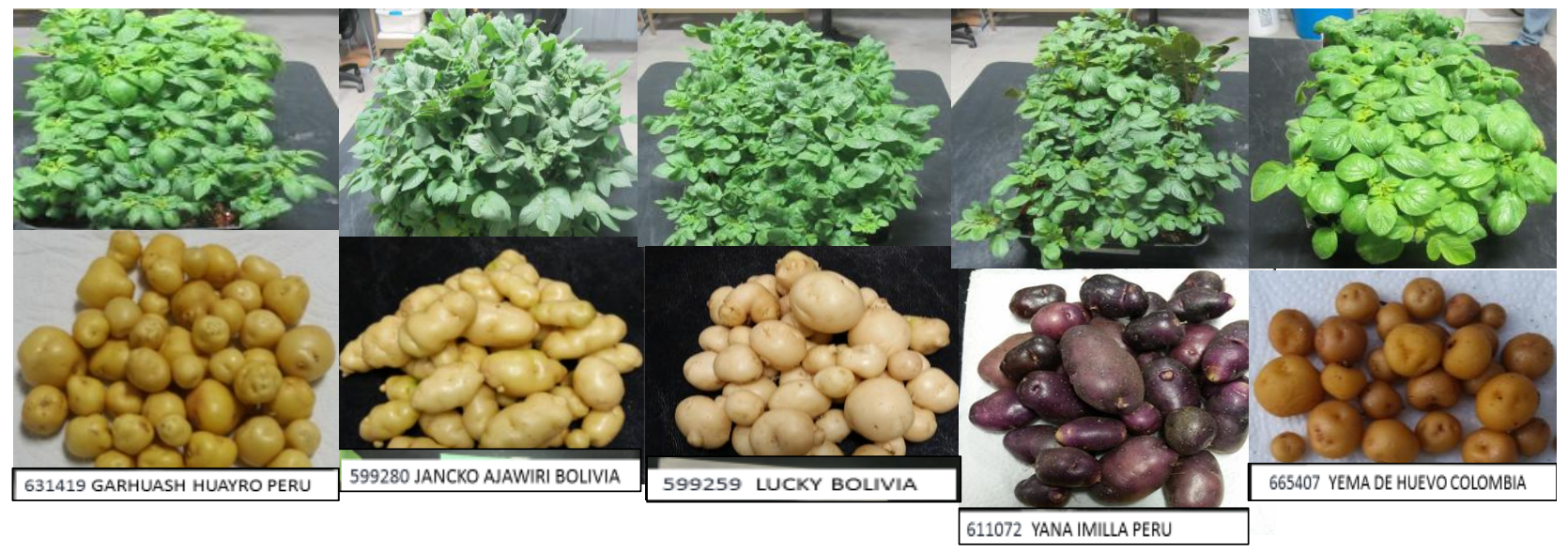

En general, los resultados estuvieron en línea de lo que se espera tradicionalmente con esta tecnología, ello es promisorio para su implementación en variedades nativas. Otro factor favorable es que la automatización de este sistema conlleva a reducción en los costos de personal. Los investigadores de este trabajo fueron testigos que una sola persona puede controlar hasta 10 fitotrones, observado en las facilidades de CETS en Wisconsin.

Finalmente, es importante enfatizar que los materiales iniciales deben estar libres de contaminación. La implementación de CETS o de cualquier otro sistema necesita contar con este requisito. Por ello los programas de semillas necesitan contar sistemas de limpieza y mantenimiento de variedades libres de contaminación. De otro modo es imposible producir semillas de calidad ya que la contaminación es perpetuada a pesar de las bondades tecnológicas de cualquier sistema.

\section{Conflictos de intereses}

Los autores no reportan conflicto de interés en el desarrollo de este estudio.

\section{Agradecimientos}

Este estudio fue completado gracias al financiamiento otorgado por CIENCIACTIVA /CONCYTEC dentro de su programa "Ideas Audaces" para el proyecto. "Producción acelerada de semilla de papa de alta calidad en el Perú potenciando la biodiversidad con tecnología de punta frente al cambio climático".

\section{Referencias citadas}

Arenas-Calle, W.C.; Cardozo Conde, C. I.; Baena, M. (2015). Análisis de los sistemas de semillas en países de América Latina. Acta Agronómica, 64(3), 239-245

Chiipanthenga, M., Maliro, M., Demo, P., \& Njoloma, J. (2012). Potential of aeroponics system in the production of quality potato (Solanum tuberosum 1.) seed in developing countries. African Journal of Biotechnology, 11(17), 3993-3999.

Ezeta, F.N. 2001. Producción de semilla de papa en Latinoamérica. Revista Latinoamericana de la Papa 12: 1-14.

Graddy, T. G. (2013). Regarding biocultural heritage: In situ political 
ecology of agricultural biodiversity in the Peruvian Andes. Agriculture and Human Values, 30(4), 587-604.

Guenthner, J. F.; Plissey, E.S.; Levi, A.E.; and Makus, L. D. (1991). The impact of the mandatory seed law on Maine potato acreage, yield, and price. Am. Potato J. 68:381-390.

Hawkes, J.G. (1990). The potato: evolution, biodiversity and genetic resources. Belhaven Press, London.

Houlihan, T. (2014). The Tools to Grow: Reduce Seed Production Cost with Phytotrons and AstroTubers ${ }^{\mathrm{TM}}$, The Badger Common Tater 66: 42-44.

Houlihan, T. (2013). CETS, LLC: A Whole New Field - A mini-interview with minituber guru, Dr. Ray Bula, The Badger Common Tater 65: 42-44.

Huamán, Z.; Spooner, D.M. (2002). Reclassification of landrace populations of cultivated potatoes (Solanum sect. Petota). Am. J. Bot. 89:947-965.

Frost, K.E.; Groves, R.L.; Charkowski, A.M. (2013). Integrated control of potato pathogens through seed potato certification and provision of clean seed potatoes. Plant Disease, 97(10), 1268-1280.

Mateus-Rodriguez, J.; de Haan, S.; Andrade-Piedra, J.; Maldonado, L.; Hareau, G.; Barker, I.; Benítez, J. (2013). Technical and economic analysis of aeroponics and other systems for potato mini-tuber production in Latin America. American Journal of Potato Research, 90(4), 357-368.

Solomon-Blackburn, R. M.; Barker, H. (2001). Breeding virus-resistant potatoes (Solanum tuberosum): a review of traditional and molecular approaches. Heredity, 86: 17 